\title{
Effect of crude oil products on the geotechnical properties of soil
}

\author{
Z. N. Rasheed ${ }^{1}$, F. R. Ahmed ${ }^{2}$ \& H. M. Jassim ${ }^{1}$ \\ ${ }^{1}$ Geotechnical Engineering Department, Faculty of Engineering, \\ Koya University, Iraq \\ ${ }^{2}$ Civil Engineering Department, Faculty of Engineering, \\ Koya University, Iraq
}

\begin{abstract}
Recently, the effects of crude oil on soil contamination have received a lot of attention from many researchers. Most of these researchers have studied the effect of crude oil itself without taking into consideration its products. Added to that, most of these outcomes have shown contradictions in their results due the addition of crude oil to the soil. Some results showed an increase in the maximum dry density while other results indicated a decrease. A similar trend was noticed in the shear strength of the soil as well.

This study seeks further investigation for evaluating the soil properties contaminated by crude oil products such as kerosene and gasoil. The aim is to develop a better understanding of the behavior of the soil exposed to oil product contamination resulting in changing its physical properties. The outcomes of this study might be guidance for designers and researchers to improve their understanding of the soil behavior in the contamination of crude oil products.

In this study, soils consisting of about $85 \%$ coarse grains and $15 \%$ fine grains, synthetically contaminated by up to $7.5 \%$ of crude oil products (based on dry soil weight) were tested. The results indicated that as the percent of contamination increased, the specific gravity, the plasticity index, the maximum dry density, the optimum moisture content, the California bearing ratio and cohesion decreased, while liquid and plastic limits, and the angle of internal friction increased. Furthermore; the results show that the effect of gasoil contamination is more than that of kerosene.
\end{abstract}

Keywords: California bearing ratio (CBR), cohesion, compaction, crude oil products, soil shear strength, index properties. 


\section{Introduction}

The contamination of land has arisen due to human activity and is essentially a legacy of our recent industrial history. Sources of contamination include the deposition of waste products, industrial operations' spills and leakages, airborne contaminated dust and repeated raising and leveling of land as one industrial use supersedes another. Contaminants may be solid, liquid or gaseous and can adversely affect susceptible targets such as people, rivers, soil, sub-soil, buildings and the environment [1].

Soil contamination by various oil products is a serious geo-environmental issue that adversely hampers the quality of soil, underground water and atmosphere. Crude oil products spillage on land is responsible for the majority of hydrocarbons contamination of earth [2]. Crude oil, or one of its products, when spilt over the ground surface percolates through the unsaturated zone where some part of it is retained there, while the rest of the portion reaches the water table causing ground water pollution. Evaporation of the retained part to the atmosphere pollutes the air, vegetation, etc. $[3,4]$.

Only a limited amount of information on the geotechnical properties of contaminated soils by crude oil products is available in literature. Most studies on contaminated soils involve leach ability and treatment studies.

It has been reported by researchers that the engineering properties of such soils are drastically changed and made unsuitable for supporting engineering structures while others refer to the notion that the contamination of soil with a proper percent of crude oil or its products will modify some of the geotechnical properties of the soil.

Purj et al. (1994) [5] studied the effect of crude oil contamination on the compaction characteristics of sand and concluded that when crude oil was used as a pore fluid, the maximum dry unit weight of sand was about 6 percent higher when compared with water as the pore fluid. The explanation for this is that oil is more effective in reducing the friction between the soil particles resulting in a reduction in the spacing between soil grains. Therefore an increase in the dry unit weight for a given compaction effort would be found. The peak shear strength, the angle of internal friction and the hydraulic conductivity was found to decrease as the percentage of oil saturation increased. They concluded that there was an increase in the relative density of the sand with an increase in the viscosity of the oil contaminant [5].

The effect of crude oil on the geotechnical properties of Kuwaiti sand was studied by Al Sanad et al. (1995) [10]. They showed in their research that the compressibility of the sand has increased due to the addition of crude oil. They found that the compaction characteristics have improved due to the addition of oil by up to $4 \%$ in weight. The coefficient of permeability has decreased by $20 \%$ and the angle of internal friction decreased when oil was added.

Vipulanandan and Elesvwarapu (2008) [7] studied the effect of kerosene contamination on the index properties and compaction characteristics of clayey soil [7]. The results showed that the liquid limit increased with increased kerosene content, the maximum dry unit weight for the clayey soil decreased as 
the kerosene was increased, and the optimum water content of the soils increased as the kerosene content was increased.

The effect of gasoil contamination on the geotechnical properties of clayey soils were observed by Walia et al. (2013) [1]. The results showed that the Atterberg's limits of contaminated soils were higher than that of virgin soil and the maximum dry density and optimum moisture content also dropped due to an increase in gasoil content in contaminated soil. Similar behavior was also observed on shear strength and CBR value of soil. Gasoil increases the chances of inter-particle slippage, thus reducing the shear strength of the gasoil contaminated soil.

In this study, the behavior of kerosene and gasoil contaminated poorly graded sandy silt soil was investigated for a better understanding as the various factors were isolated and independently considered.

\section{Objectives}

The objective of this research was to investigate the effect of crude oil products "kerosene and gasoil" contamination on some of the geotechnical properties of poorly graded sandy silt soil.

\section{Materials and methods}

\subsection{Soil}

The experimental work was conducted with soil, procured from the Haibat Sultan Mountain that is situated between the lowest mountains in the south and the highest mountains in the north of the Iraqi Kurdistan region. It extends from NW to SE, which has an elevation of about $1200 \mathrm{~m}$ above sea level and $440 \mathrm{~m}$ with respect to the adjacent Koya plains [8]. The soil samples were obtained at a depth $0.5-1.0$ meter from ground surface.

The analysis showed that the tested soil samples have a specific gravity of 2.62. The grain size distribution of the soil, based on the sieve and hydrometer analysis, is shown in Figure 1. The percent of gravel was $24 \%$, and the percent of sand was $61 \%$, while the percent passing from sieve \#200 was $15 \%$, the soil has a mean particle diameter $\left(\mathrm{D}_{50}\right)$ of $0.6 \mathrm{~mm}$, a coefficient of uniformity $(\mathrm{Cu})$ of 60 and a coefficient of curvature $(\mathrm{Cc})$ of 0.6 . The index properties of the virgin soil were 30.3 for liquid limit and 26 for plastic limit. The soil was classified as "SP-SM" as per the Unified Soil Classification System. The maximum dry density and optimum moisture content from standard compaction test was $17.79 \mathrm{kN} / \mathrm{m}^{3}$ and $8.3 \%$, respectively.

\subsection{Gasoil and kerosene}

The soil was contaminated in the laboratory with varying percentages of gasoil and kerosene as the contaminants, to study the contaminant's effect on various geotechnical properties of soils. The density of gasoil used in this study is $820 \mathrm{~kg} / \mathrm{m}^{3}$ while the density of kerosene is about $640 \mathrm{~kg} / \mathrm{m}^{3}$ at $15^{\circ} \mathrm{C}$. 


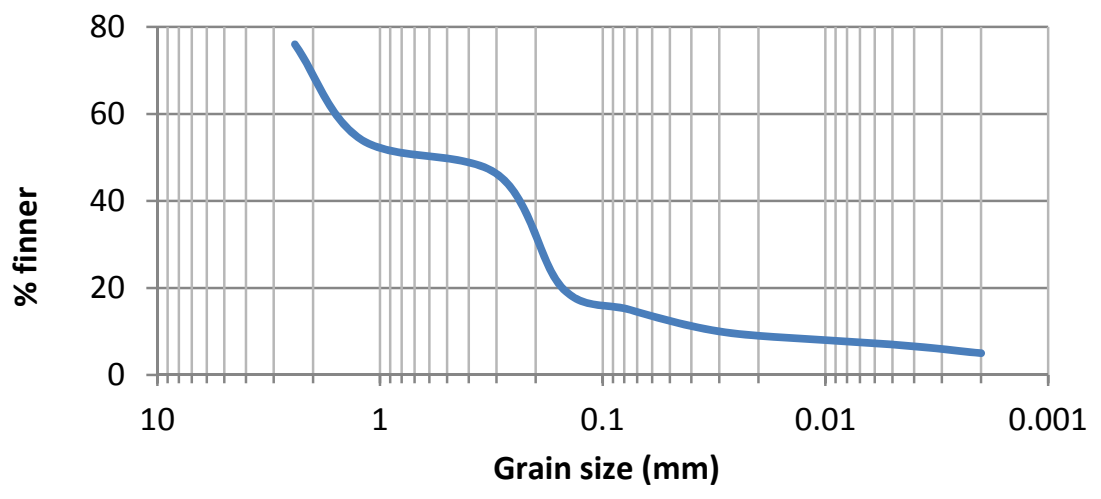

Figure 1: Grain size analysis.

\subsection{Procedure of contamination}

Initially, the soil was air dried and hand sorted to remove any undesired matter. It was then oven dried and contaminated by kerosene or gasoil in varying percentages, i.e. $3 \%, 5 \%$ and $7.5 \%$ by dry weights and kept for a one day period of time to ensure thorough absorption of contaminant in the soil and then tested to determine their physical and engineering properties.

\subsection{Laboratory test procedures}

Soil index properties, particle size analysis and classification, moisture content, specific gravity, compaction, California bearing ratio (CBR) and direct shear tests were performed for the contaminated and the uncontaminated soil with gasoil and kerosene.

Geotechnical laboratory tests were conducted at the soil mechanic laboratory, Koya University, Iraq, according to ASTM "American Society for Testing and Materials" [9].

\section{Analysis and discussion}

\subsection{Specific gravity}

Specific gravity test was carried out on virgin and contaminated soils according to ASTM D 854-00 - Standard Test for Specific Gravity of Soil Solids by Water Pycnometer. Gasoil has decreased the specific gravity of soil from 2.62 to 2.27 while Kerosene has decrease the specific gravity of soil from 2.62 to 2.46 as the contamination content in the soil increased from 0 to $7.5 \%$. Figure 2 shows the variation in specific gravity of virgin and contaminated soil sample, it also shows that the decrease in specific gravity for soil contaminated with gasoil is more than that by kerosene. 


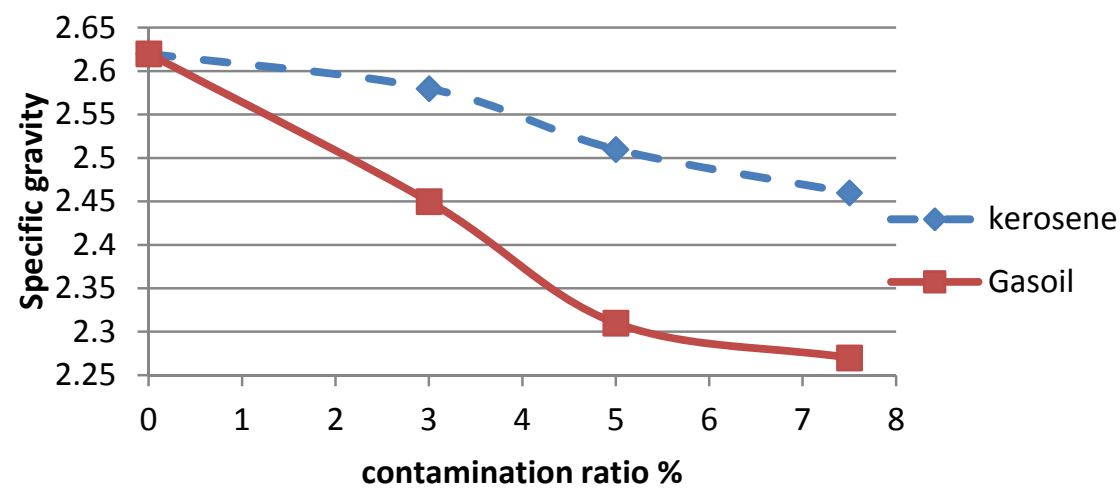

Figure 2: Specific gravity - kerosene and gasoil contamination ratio.

\subsection{Liquid limit and plastic limit (ASTM D 4138)}

The mechanical properties of a fine grained soil, mostly clay, are altered by changing the water content. The plasticity index for cohesionless soils is zero since they do not exhibit plastic state. The results of THE liquid limit and plastic limit tests on different soil mixes with and without kerosene or gasoil are summarized in table 1.

Figure 3 shows the variation of liquid limit, plastic limit and plasticity index with contamination content in the soil. The liquid limit and plastic limit values increased while the plasticity index decreased as the contamination content in the soil varied up to $7.5 \%$. As the gasoil content in the soil increased from 0 to $7.5 \%$, the liquid limit and plastic limit increased by $21.6 \%$ and $31.6 \%$, respectively, while the plasticity index decreased by $36.7 \%$. Same behavior was observed with kerosene contamination, the liquid and plastic limits increased by $12 \%$ and $18.3 \%$ respectively while the plasticity index decreased by $26.7 \%$.

Table 1: Summary of liquid and plastic limits for virgin and contaminated soil.

\begin{tabular}{|c|c|c|c|c|c|c|}
\hline \multirow{2}{*}{$\begin{array}{c}\text { Contamination } \\
\%\end{array}$} & \multicolumn{2}{|c|}{ Liquid limit } & \multicolumn{2}{c|}{ Plastic limit } & \multicolumn{2}{c|}{ Plasticity index } \\
\cline { 2 - 7 } & gasoil & kerosene & gasoil & kerosene & gasoil & kerosene \\
\hline $0 \%$ & 30.3 & 30.3 & 26 & 26 & 4.3 & 4.3 \\
\hline $3 \%$ & 33.45 & 31.25 & 30 & 27.2 & 3.45 & 4.05 \\
\hline $5 \%$ & 35.26 & 32.67 & 32.15 & 29.2 & 3.11 & 3.47 \\
\hline $7.5 \%$ & 36.84 & 33.93 & 34.12 & 30.78 & 2.72 & 3.15 \\
\hline
\end{tabular}



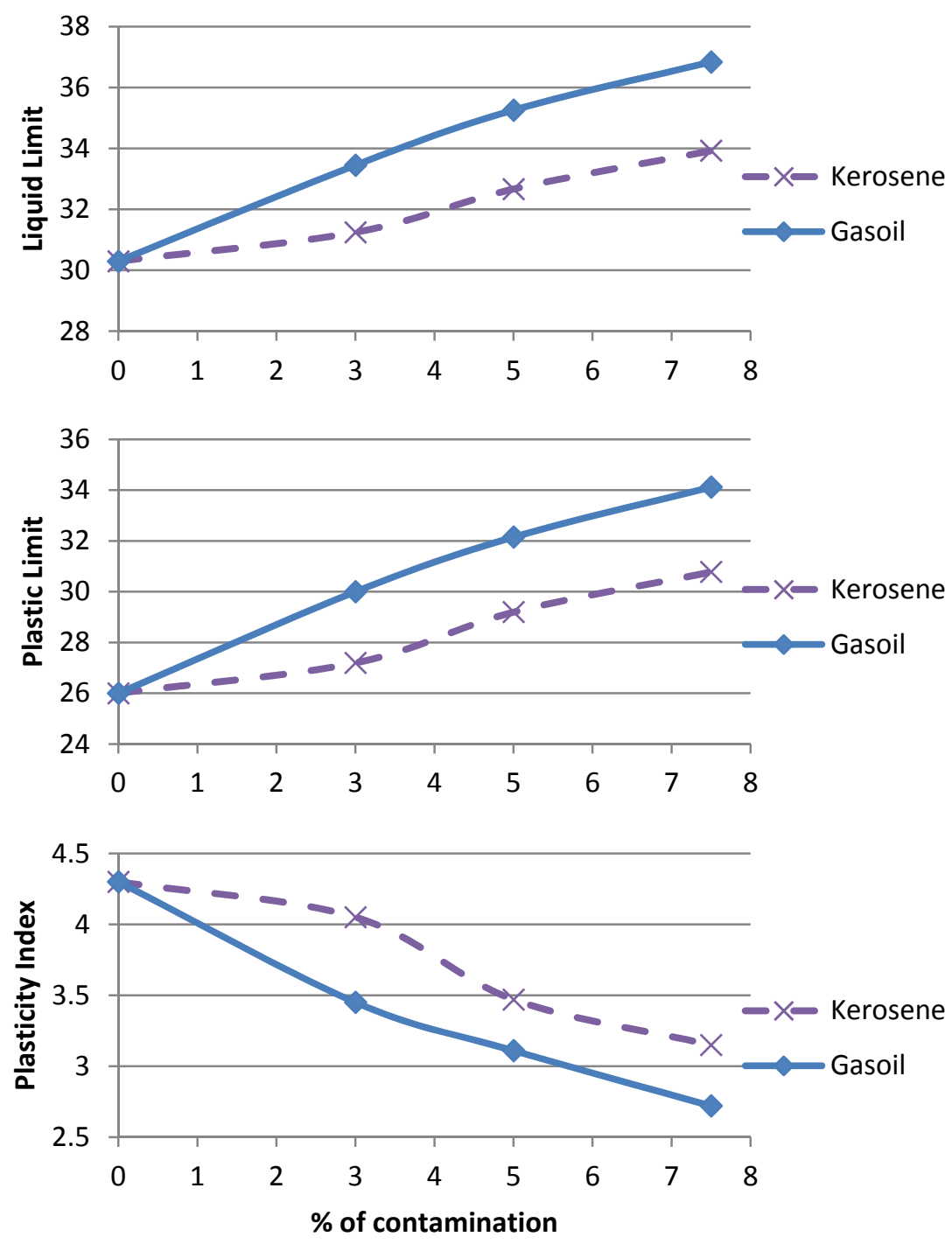

Figure 3: Liquid limit, plastic limit and plasticity index-contamination ratio.

\subsection{Compaction characteristics}

Compaction tests confirmed ASTM D 698 - Standard Test Methods for Laboratory Compaction Characteristics of Soil Using Standard Effort (600 $\left.\mathrm{kN} \cdot \mathrm{m} / \mathrm{m}^{3}\right)$. The maximum dry density and optimum moisture content of contaminated soil slightly decreased. Figure 4 shows that the maximum dry density and optimum moisture content dropped due to an increase in oil content in contaminated soils. When soils are contaminated with polar organic liquids, the 
soil structure tends to be of a dispersed structure. This dispersed structure reduces dry density of soil. The results also show that at $7.5 \%$ of contamination, the reduction in maximum dry density and optimum moisture content for soil contaminated by kerosene is less than that by gasoil with $5.4 \%$ and $10.3 \%$ respectively.
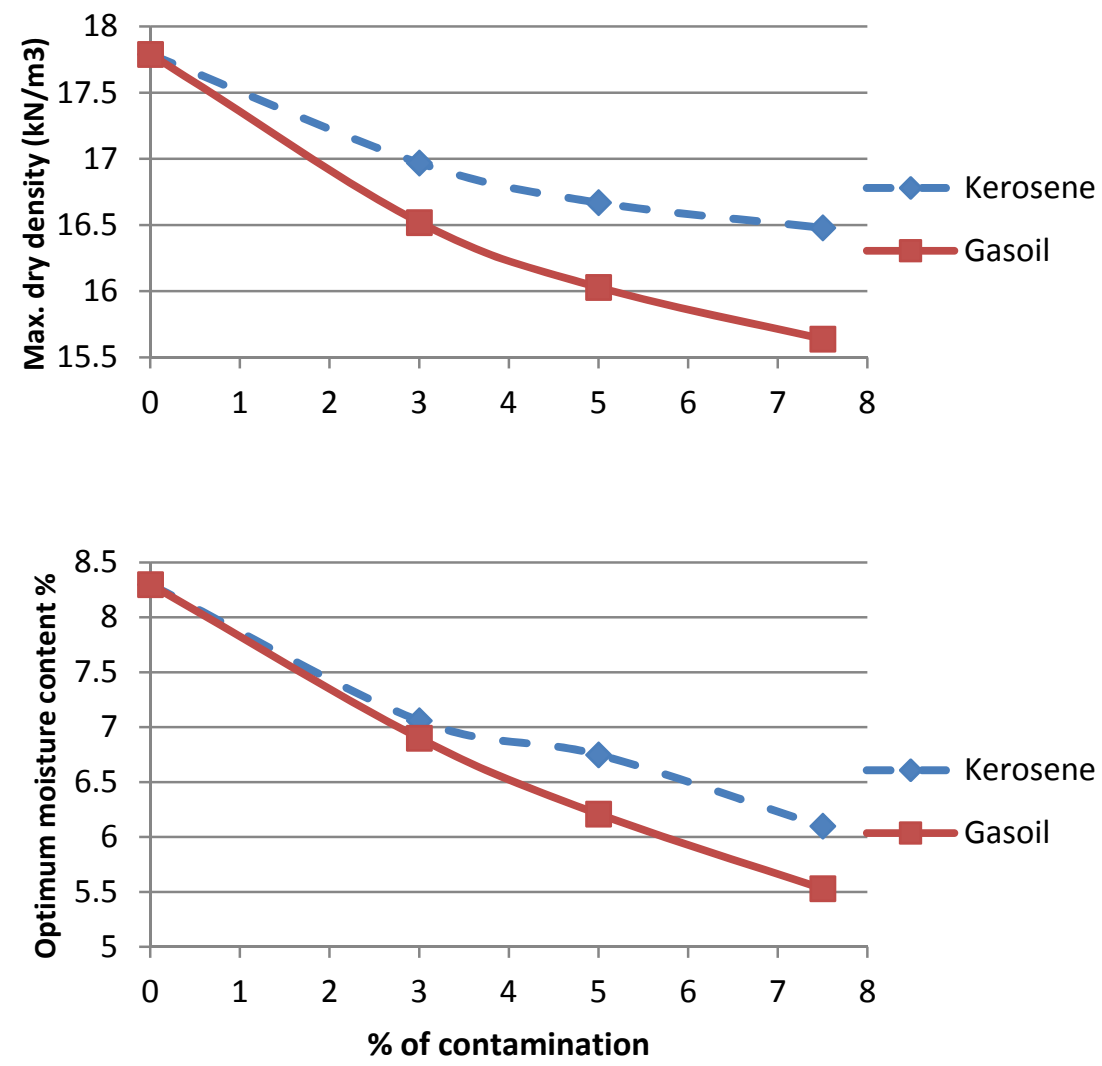

Figure 4: Effect of contamination ratio on the compaction parameter of soil.

\subsection{Shear strength parameters}

Shear strength of the virgin soil and also of all the soil contaminant mixes was determined by direct shear tests on remolded samples obtained from compaction at optimum moisture content for each contamination percent based on ASTM D 3080 - Standard Test Method for Direct Shear Test of Soils under Consolidated Drained Conditions. Figure 5 summarize the results obtained from the direct shear test in terms of the angle of the internal friction and soil cohesion, respectively. The results show that the cohesion between soil particles decreases, while the 
angle of internal friction increases, with the increasing of the contamination percent. Crude oil products increase inter-particle slippage, thus reducing the cohesion of contaminated soil and, as a result of this behavior, the angle of internal friction increased.
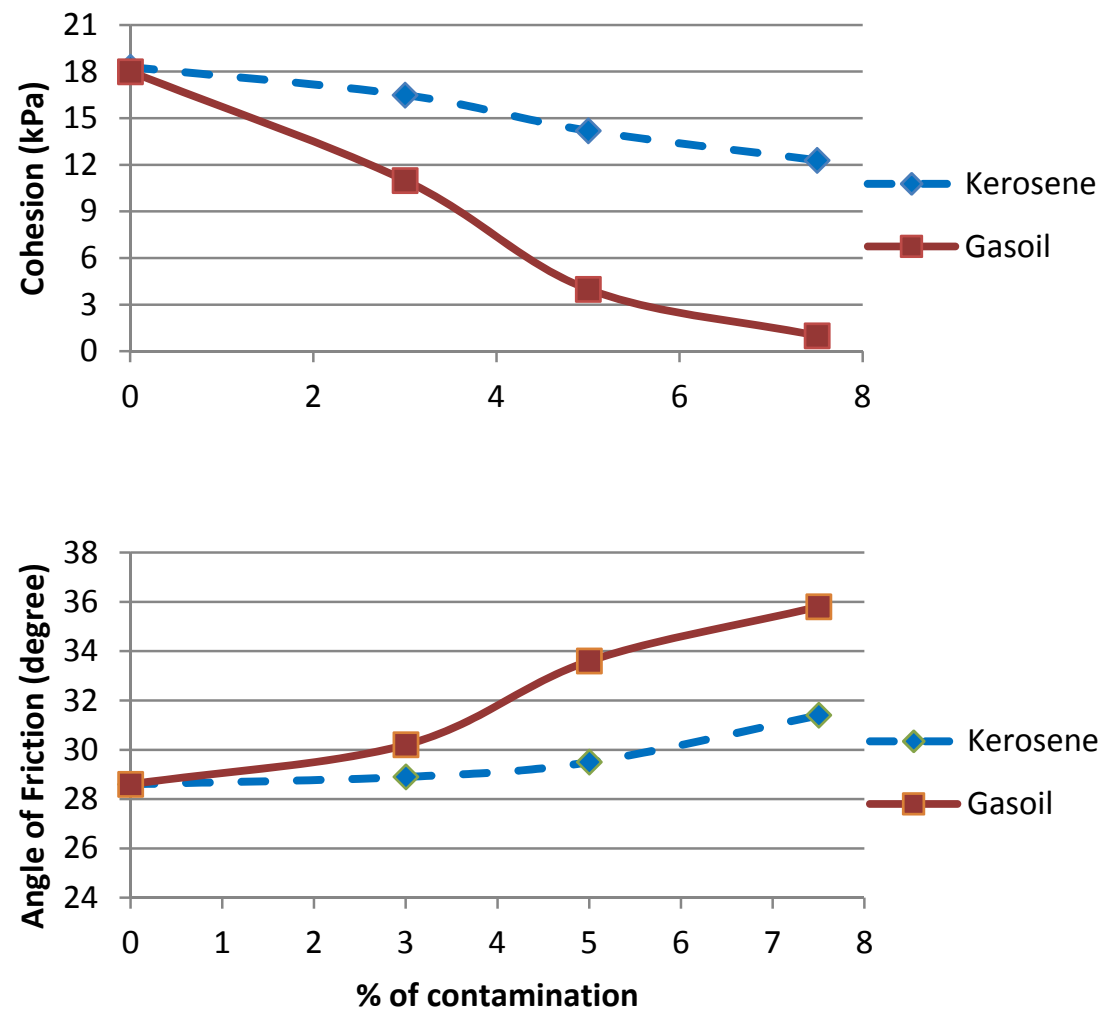

Figure 5: Effect of contamination on the shear strength parameters.

\subsection{California bearing ratio (CBR)}

The California bearing ratios (CBR) of the treated soil samples were evaluated according to ASTM D 1883-05 Standard Test Method for CBR of Laboratory Compacted Soil. The results showed that there was a decrease in the shear strength of the contaminated soil. The CBR value was seen to be decreasing from $3.7 \%$ to $2.2 \%$ as the percentage of kerosene contaminant increased from 0 to $7.5 \%$, while a decrease to 1.8 as the percentage of gasoil contamination was increased to $7.5 \%$, as shown in Figure 6. Furthermore, at $7.5 \%$ contamination, the reduction in shear strength using kerosene contamination was less than that using gasoil by about $18 \%$. 


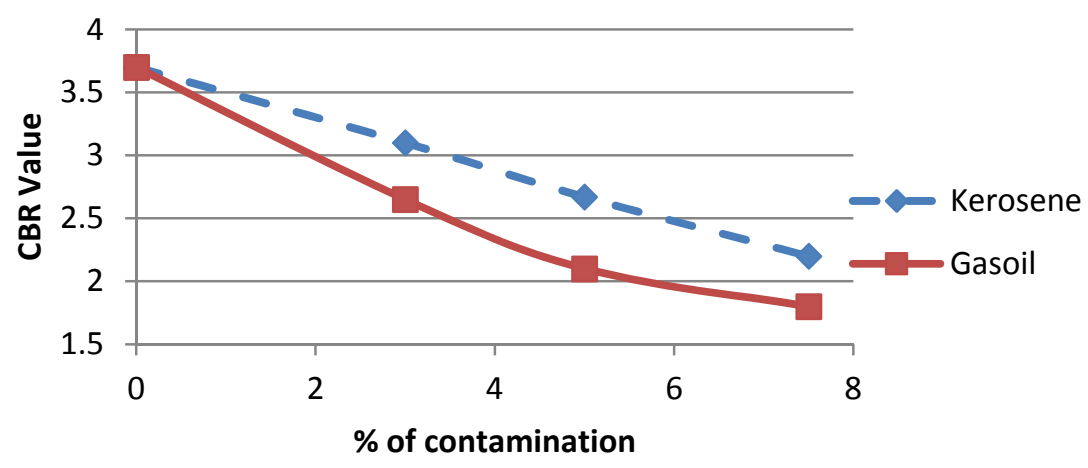

Figure 6: Effect of the contamination on the CBR values.

\section{Conclusions}

In this study, the effects of crude oil products contamination on geotechnical properties were observed and the following can be concluded:

1. The liquid and plastic limits of contaminated soils were higher than that of virgin soil and increased with an increase in the contamination ratio, while the specific gravity and plasticity index decreased.

2. The maximum dry density and optimum moisture content also dropped due to an increase in the contamination ratio.

3. Similar behavior was also observed on cohesion and the CBR value of soil, while the angle of the internal friction was increased.

4. The results show that the gasoil contamination effects are more than that by kerosene, such that the drop ratios in specific gravity, plasticity index, maximum dry density, optimum moisture content, cohesion and CBR value were $16.3 \%, 15.8 \%, 5.4 \%, 10.3 \%, 92 \%$ and $18.2 \%$, compared to kerosene effect values respectively, while the increase in the liquid limit, plastic limit and angle of internal friction using gasoil were $8.6 \%, 10.9 \%$ and $15.8 \%$ more than that by kerosene, respectively.

5. This study will be helpful for the reuse of contaminated soils in construction work.

\section{References}

[1] Professor B.S. Walia, Asst. Prof. G. Singh, Asst. Prof. M. Kaur, Study Of Diesel Contaminated Clayey Soil, Proceedings of Indian Geotechnical Conference December 22-24, pp 1-5, 2013.

[2] American Petroleum Institute, Sampling and analysis of gasoline range organics in soils. American Petroleum Institute Publication, No. 45 16, 1991. 
[3] Hinchee, R.E. and Olfenbuttel, R.F. Butterworth-Heinemann, in Situ Bioreclamation: Application and Investigations for Hydrocarbon and Contaminated Site Remediation. Ed. by. London. pp. 125-142.

[4] Dineen. D., Slater, J.P., Jicks, P. and Holland, In situ biological remediation of petroleum hydrocarbons in unsaturated soils, Hydrocarbon Contaminated Soil and Ground Water: Analysis, Fate, Environmental and Public Health Effects, Remediation. Ed by Kostecki, P.T. and Calabrese, E. J. Vol. 1. Lewis Publishers, Chelsea, Mich., pp. 177-187, 1990.

[5] Purj, V.K., B.M. Das, E.C. Cook and E.C. Shin, "Geotechnical Properties of Crude Oil- Contaminated Sand". ASTM Special Technical Publication, 1221, 7 Y 5-88, 1994.

[6] Dana B. Al-Duwaisan, Ahmad A. Al-Naseem, Kuwait Oil Lakes, IACSIT Press, Singapore Characterization of Oil Contaminated Soil, $2^{\text {nd }}$ International Conference on Environmental Science and Technology, IPCBEE vol. 6, pp. 439-442, 2011.

[7] C. Vipulanandan, Ph.D., P.E.1, and P. Elesvwarapu, Geocongress, Geotechnics of Waste Management and Remediation, ASCE, M.S.2, pp. 804-811, 2008.

[8] Hamasur, Gh. A., Engineering, "Geological study of rock slope stability in Haibat Sultan area", NE Iraq. UN pub. M.Sc. thesis, University of Salahaddin, Erbil, Iraq, p. 153, 1991 (in Arabic).

[9] Braja M. Das, "Soil Mechanics Laboratory Manual" Sixth Edition, Oxford University Press, New York, 2002.

[10] H. Al-Sanad, W.K. Eid, and N.F. Ismael, "Geotechnical Properties of OilContaminated Kuwait Sand", Journal of Geotechnical Engineering, No. 5, Vol. 121, pp. 407-412, May 1995. 